\title{
Living with Kallmann Syndrome - Analysis of Subjective Experience Reports from Women
}

\author{
Leben mit dem Kallmann-Syndrom - \\ Analyse subjektiver Erfahrungsberichte von Frauen
}

Authors

Affiliations
J. Hofmann ${ }^{1}$, M. Watzlawik ${ }^{2}$, H. Richter-Appelt ${ }^{1}$

${ }^{1}$ Institute and Polyclinic for Sex Research and Forensic Psychiatry, University Medical Centre Hamburg-Eppendorf, Hamburg

${ }^{2}$ Institute of Psychology, University of Osnabrück, Osnabrück

\section{Key words \\ - adolescence \\ - hormone replacement \\ - puberty \\ - disturbance of puberty \\ Schlüsselwörter \\ - Adoleszenz \\ - Hormonsubstitution \\ - Pubertät \\ - Störung der Pubertät}

Deutschsprachige Zusatzinformationen online abrufbar unter: www.thieme-connect.de/ ejournals/toc/gebfra

$\begin{array}{ll}\text { received } & 15.4 .2013 \\ \text { revised } & 21.5 .2013 \\ \text { accepted } & 9.8 .2013\end{array}$

Bibliography

DOI http://dx.doi.org/

10.1055/s-0033-1350881

Geburtsh Frauenheilk 2013; 73:

1112-1120 @ Georg Thieme

Verlag KG Stuttgart · New York . ISSN 0016-5751

Correspondence

Prof. Dr. phil.

Hertha Richter-Appelt

Institut für Sexualforschung und Forensische Psychiatrie

Universitätsklinikum

Hamburg-Eppendorf

Martinistraße 52

20246 Hamburg

hrichter@uke.de

\section{Abstract \\ $\nabla$}

Five women were questioned on their experiences with Kallmann Syndrome (KS) in thematically focused, open interviews. This investigation complements the study of the experiences of men with KS [1]. The results show that the consequences and pressures of KS extend beyond the somato-medical field and that those affected are also burdened by mental and psycho-social impacts. The pressures experienced by those affected include a distorted body image resulting from the lack of physical development, which in turn leads to difficulties in developing a healthy feeling of self-worth. Furthermore, particular attention should be paid to the influence of hormone therapy on mood and libido during medical treatment. Some of the affected women reported experiencing depressive moods and low libido, and pressures in their relationship associated with this. The affected women wanted KS to be viewed as a whole in order to achieve better handling. In particular, attentive handling of issues relating to fertility was important to them. Additional relevant support included offers of confidential discussions, and offers of psychotherapy and, where required, sex education or sex therapy.

\section{Introduction and Status of Research $\nabla$}

Physical symptoms

$\mathrm{KS}$ is part of the clinical picture of hypogonadotropic hypogonadism $(\mathrm{HH})[3,4]$. A congenital genetic defect causes the body's own oestrogen production (or testosterone production in affected men) to be disrupted $[3,4]$. The prevalence of KS is 1:40000 among women [5]. It is diag-

\section{Zusammenfassung \\ $\nabla$}

Mit thematisch fokussierten, offenen Interviews wurden 5 Frauen zu ihren Erfahrungen mit dem Kallmann-Syndrom (KS) befragt. Diese Untersuchung komplementiert die Studie zu den Erfahrungen von Männern mit KS [1]. Die Ergebnisse zeigen, dass die Folgen und Belastungen des KS über den somatomedizinischen Bereich hinausgehen und dass die Betroffenen auch durch psychische und psychosoziale Auswirkungen belastet sind. $\mathrm{Zu}$ den von den Betroffenen wahrgenommenen Belastungen gehört ein gestörtes Körperbild als Folge der ausbleibenden Körperentwicklung, das wiederum zu Schwierigkeiten bei der Entwicklung eines gesunden Selbstwertgefühls führt. Des Weiteren sollte bei der medizinischen Behandlung besonders auf den Einfluss der Hormontherapie auf Stimmung und Libido geachtet werden. Betroffene Frauen berichteten z.T. von depressiven Stimmungen sowie von niedriger Libido und von damit verbundenen Belastungen in ihrer Beziehung. Die betroffenen Frauen wünschten sich für einen besseren Umgang einen ganzheitlichen Blick auf das KS. Insbesondere war ihnen ein achtsamer Umgang mit Fragen zur Fertilität wichtig. Weitere relevante Unterstützungen waren vertrauensvolle $\mathrm{Ge}$ sprächsangebote, psychotherapeutische und bei Bedarf sexualpädagogische oder sexualtherapeutische Angebote.

nosed much more rarely in women than in men (prevalence $1: 8000$ to $1: 10000$ ) [6]. KS differs from other forms of $\mathrm{HH}$ due to a limited or absent sense of smell (anosmia) [5,7,8]. Women with KS have very low LH (luteinising hormone) levels and FSH (follicle-stimulating hormone) levels in their blood. The reason for this is a lack of $\mathrm{GnRH}$ (gonadotropin-releasing hormone), which in turn is the cause of female ovary dysfunction $[9,10]$. 
The physical effects of this lack of sex hormones are insufficiently developed secondary sexual characteristics $[9,10]$. The symptoms experienced by affected women are a lack of menstruation (primary amenorrhea), no breast development $[8,11]$, small ovaries, an absence of folliculogenesis, and no development of gametes [11]. Normal pubic hair can also be absent due to the lack of oestrogen or nevertheless develop due to the hormones of the adrenal gland $[8,12]$. The lack of oestrogen causes vaginal dryness, which is often painful and unpleasant for those affected. The sex hormone deficiency leads to lower sexual needs, less sexual contact and infertility [13]. Prepubescent growth is normal. However, affected women fall behind in growth during puberty $[11,14]$. The absent pubescent growth spurt is nevertheless made up for during the time following puberty $[8,14]$. As a result of the lack of oestrogen, osteoporosis occurs frequently in sufferers [8]. KS in women (as well as in men) is treated with sex hormones. In order to stimulate the physical development of sexual characteristics, the administering of oestrogen is begun, initially at a low dose of $1 \mathrm{mg}$ of oestradiol, then slowly increasing in dose $[8,12$, 15]. From the 2nd year of treatment, the oestradiol is supplemented with chlormadinone acetate $[12,15]$. If there is a desire for pregnancy, treatment with GnRH is recommended to stimulate the production of LH and FSH. The chances of success of this treatment are estimated as good [10]. Alternatively, LH or FSH can be administered directly $[8,10]$.

It is possible to diagnose KS prior to puberty; the absence of a sense of smell (anosmia) can be an indicator here [15]. It is important to test the sense of smell using a smell test [8] in order to distinguish KS from delayed puberty and other forms of $\mathrm{HH}$ $[8,12]$. The symptoms of KS become apparent during puberty if no physical pubescent development occurs after the 13th year of life. However, a medical investigation is advised if no breast growth has yet occurred in girls by the age of 14.5 years at the latest [12]. Primary amenorrhea is found in $90 \%$ of women with $\mathrm{HH}$ [15]. KS is diagnosed by investigating the development of secondary sexual characteristics, by examining the family history, and using a cranial CT or MRI. The concentrations of LH, FSH, PBI and oestradiol in the blood of those affected are examined, as these are very low in KS [15]. Kallmann Syndrome is also diagnosed in women in connection with investigations into an unfulfilled desire to have children [16].

\section{Mental impacts}

Medical research is primarily concentrated on the somatic backgrounds and aspects of KS. Studies of the physical symptoms of KS enable conclusions to be drawn that mental impairment and pressures also occur as a result of the absent physical pubescent development and lack of oestrogen in KS.

Tsimaris, Vrachnis, Iliodromiti and Deligeorglou [13] indicate the difficult situation of pubescent girls diagnosed with $\mathrm{HH}$. The emotions of the girls and parents are described as "shocked", "confused" and "devastated" ([13], S. 2). This is caused by the fear of infertility and stigmatisation due to the illness [13]. Parental understanding and encouragement are advised to support girls during mood swings. The risk that those affected can become insecure and withdrawn due to $\mathrm{HH}$ is highlighted [14]. In connection with delayed puberty, Land [14] shows that delayed physical maturation in children can cause "considerable mental conflict situations" (p. 633). It is also advised that affected girls are encouraged not to seek the causes of HH within themselves [13]. Young women feel significantly restricted in their sexuality due to the low libido caused by KS [13]. This can lead to severe psy- chosexual pressures in later life. Well-coordinated oestrogen treatment and, where necessary, sex therapy are recommended as support [13]. The treatment guidelines of the German Society of Paediatrics and Adolescent Medicine [15] and Han and Bouloux [17] advise that girls and boys with KS receive psychotherapy in severe cases. Individual example cases from studies of men with KS [18-22] show insecurities, self-esteem problems and social exclusion as an indirect consequence of the lack of physical development.

As there is a sex hormone disturbance in KS, it could be assumed that a gender identity disorder is possible. There are hardly any research findings into an atypical development of sexual identity in women with KS. Meyenburg and Sigusch [24] report on just two cases where gender identity developed atypically in men, so, analogously to this, it can be assumed that an undisturbed and unremarkable gender identity also develops in women with KS.

The British psychotherapist Neemuchwala described in his case reports [20-22] that patients experience both mental and social difficulties as a result of the disrupted physical development, caused by insecurities with regard to their own bodies. The insecurity of patients ranges from feelings of shame to an impairment in self-image and self-esteem [20-22]. Neemuchwala [20-22] and Bobrow et al. [19] report on exclusion and harassment by peers. Hefner et al. [18] indicate difficulties in mental and sexual development as well as self-doubt resulting from eunuchoid habitus due to negative experiences of sexual development. Even though there is a lack of corresponding findings in women with regard to the consequences of KS, it seems likely that such experiences and limitations are also perceived by women.

In a field report written in the form of a first-person account [23], a female student reports on her experiences with KS. During the pubescent period, she developed strong feelings of alienation from her peers when these underwent further physical developments. The author disguised herself to appear "normal" (ibid., p. 9). She developed a high level of dissatisfaction with her body and, subsequently, self-esteem problems. She stated that the absent puberty was something to which she "was not entitled" (ibid.). The author described her confusion about this and her inability to express the lack of development in words, as well as to talk about her shame and fear regarding her lack of physical development. The mental pressures also remained when she was diagnosed and received hormone treatment. The author emphasises that she never experienced pain due to the somatic stress, and the stresses caused by KS were of a purely psychosocial nature. The impairments became clear to her in a social setting and could not be rectified using hormone therapy. Ultimately, the author was able to work on her mental difficulties with the help of psychotherapy.

In order to gain more data material on these mental accompanying symptoms and the experience of KS among patients, which is essential for the targeted support of patients, a study was conducted on the mental impacts of KS at the University Medical Centre Hamburg-Eppendorf. A qualitative approach was chosen for this research project in order to investigate the stresses experienced from the viewpoint of patients. The present investigation complements the study on men with KS. [1]. Research findings from a comparison between the mental impacts of KS in men and women are also being prepared for publication.

The central research questions for the investigations into the mental impacts of KS in women are: 


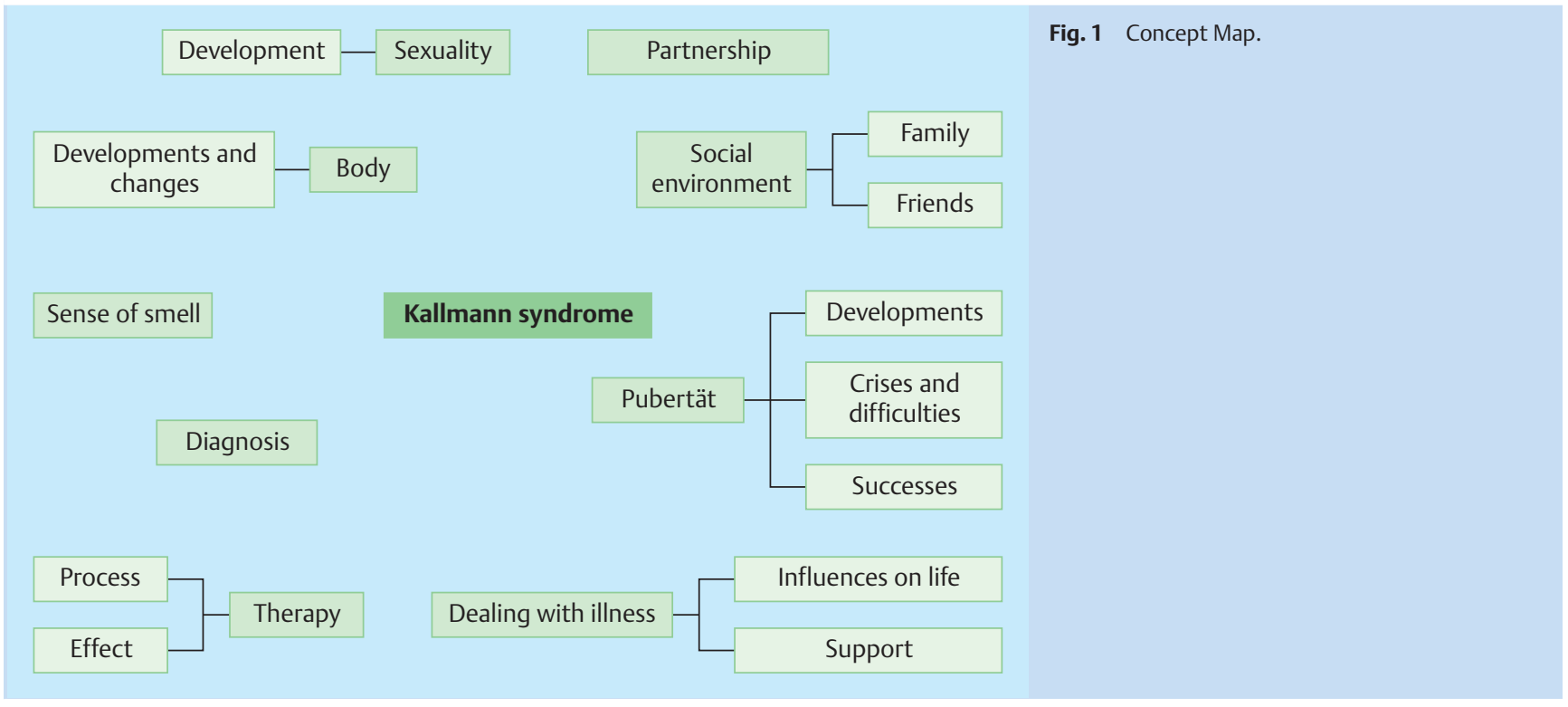

1. What experiences and stresses are perceived by women with KS in the areas of life affected by KS? Here, there is the key question of which areas of life are influenced by the absent physical and sexual development in KS?

2. Which coping strategies with regard to the lack of physical development prove to be successful from the women's viewpoint?

\section{Methodology}

The present investigation is part of a larger research project by the University Medical Centre Hamburg-Eppendorf into the mental impacts of Kallmann Syndrome. The Ethics Commission of the Hamburg Chamber of Psychotherapists has approved this project.

A qualitative research design was chosen in order to produce the largest possible quantity of data to explore and structure the field. Open interviews were conducted with the study participants in a two-person setting. In addition to this qualitative data collection, data were collected with questionnaires, the results of which will be published elsewhere. The questionnaires looked at demographic and social aspects, physical characteristics and their development, diagnosis and treatment measures, the experience of puberty, and sexuality. The following standardised questionnaires were also presented to the participants for completion: Questionnaires on Gender Identity, Bem Sex-Role Inventory, Fbek, BSI, Dissociation Questionnaire (DIS-Q), Questionnaire on Life Satisfaction (FLZ).

\section{Acquisition of participants}

Prior to the study, practice-based doctors and hospital-based doctors in the fields of Endocrinology, Gynaecology and Reproductive Medicine throughout Germany were informed and consulted about the project. The aim was to find men and women diagnosed with KS to participate in interviews. Contacts with self-help groups were used as an additional acquisition source. An information sheet was published on websites and newsgroups relating to $\mathrm{KS}$, hypogonadism, a desire to have children, and endocrinology in order to draw attention to the study, provide information on the study and obtain participants.

\section{Implementation}

To collect the individual experiences of those affected, individual interviews (two-person setting) were conducted with the aid of a concept map ( Fig. 1) developed specially for this project.

This "map", which is based on previous research findings, was presented to the interviewees after the introductory phase to encourage the narrative flow and permit additional topic-focussed information to be obtained [25]. This technique proved to be particularly helpful in order to give some structure to the topic area and yet enable the interview partners to report on their own experiences in as open and free a manner as possible. It was explicitly highlighted that the Concept Map was intended to provide suggestions, but the interview partners were not restricted to the stated areas.

The interview technique enabled the participants (Ps) to represent their experiences in a very personal way, as well as to highlight and address relevant aspects [26,27] subjectively. All the key subjects were generally tackled by the Ps without prompting, which is a good indication that the key topics in the Concept Map largely match the experiences of the Ps. More in-depth questions were also asked where required. These questions were developed based on literature research. The interviews were conducted in neutral settings. The interviews lasted 45 to $109 \mathrm{~min}$ (range $64 \mathrm{~min}$, average duration $65 \mathrm{~min}$ ) and were recorded with digital recording equipment. The transcription was performed according to the transcription rules of Lucius-Hoene and Deppermann [28].

\section{Random sample description}

Five women diagnosed with KS took part in the study between April 2009 and December 2009. Three of these were acquired over the Internet, two joined on the recommendation of their doctors. The average age of the Ps was 30.8 years. KS was diagnosed on average at 22.8 years. All the Ps had obtained their German school-leaving qualifications (Abitur). The initial diagnosis states the age at which the Ps first attracted medical attention. Despite the small patient sample $(n=5)$, average ages and the 
Table 1 Age and time of diagnosis for the Ps at the time the women were surveyed

\begin{tabular}{|c|c|c|c|c|}
\hline Participant No. & Name/synonym & Age in years & Age at initial diagnosis in years & Age at KS diagnosis in years \\
\hline 1 & Jeannette & 24 & 11 & 15 \\
\hline 2 & Laura & 31 & 10 & 21 \\
\hline 3 & Marie & 44 & 18 & 35 \\
\hline 4 & Paula & 31 & 16 & 31 \\
\hline 5 & Stephanie* & 24 & 12 & 12 \\
\hline Mean value & & 30.8 & 13.4 & 22.8 \\
\hline Standard deviation & & 7.30 & 3.07 & 8.91 \\
\hline Median & & 31 & 12 & 21 \\
\hline Range & & 20 & 7 & 23 \\
\hline
\end{tabular}

* KS was diagnosed in the patient directly after KS was diagnosed in her brother.

standard deviation were calculated. The detailed data can be found arranged in $\odot$ Table 1.

\section{Evaluation}

The evaluation took place following the qualitative content analysis according to Mayring [2] and with the aid of the MAXQDA 10 (MAX Qualitative Data Analysis) evaluation programme. Interview sequences were allocated to categories. Both inductive and deductive logic were applied in the course of this. Some of the categories were developed from research concepts based on the Concept Map and guiding questions (see $\odot$ Fig. 1, e.g. according to experiences during diagnosis). The interviews enabled the topics suggested by the Concept Map to be substantiated or elaborated using individual experience. Other categories only arose when the Ps mentioned them and thus represented new aspects that had been given little consideration until that time. The results are shown below.

\section{Results}

The responses to the first question are shown below according to category. Each section represents a category; a summary is given in Table 3. Personal experiences are shown using quotations in the words of the interview partners. A summary of results is given in Table 4.

\section{Body perception and shame}

When asked how they perceived their bodies before starting hormone therapy, the Ps reported on confusion and insecurity regarding the absence of their expected pubescent physical development. The women also said that they had an "inkling" that they "were different". As it became clear that the other girls had "passed them by" in their physical development, they became aware that their development was lagging behind.

And then they all pulled away and I stayed still, in every respect: height, build, interests. All the things that happen then. (Jeannette, 24 years)

I was twelve, thirteen at this summer camp. When I saw my past best friend in the shower, and that she was also wearing a bra, it felt like such a betrayal. As in: oh, no, not you as well, don't you leave me now too. Because I noticed that they were changing in a way that I couldn't keep up with. (Jeannette, 24 years)
I always thought that I just wasn't a normal woman. (Laura, 31 years)

In addition to the lack of physical development, the absence of menstruation played a crucial role as, for the Ps, it was a symbol of the absence of their maturation into women. The childlike body was not feminine enough for them and they were therefore ashamed of it. This was expressed in shyness towards their peers. Three Ps said that they also remained childlike in terms of their interests and did not share the pubescent interests of their peers ("Boys, make-up, buying bras, fashion") (Jeannette, 24 years). One P reported that she still "feels like a little girl" today (Paula, 31 years)

I'll never have periods and I found that really embarrassing, as this makes me different as well. I was so shy. I wasn't really a huge outsider, but inside I really felt like that. (Marie, 44 years)

The Ps told themselves they were a "late bloomer" (Paula, 31 years) to explain their condition. A medical diagnosis was initially delayed in the hope of a simple solution, which was supposed to appear in a natural way without the patients doing anything.

I am now 31 and, of course, I didn't just notice yesterday that something isn't right. I didn't have any periods that began on their own and the other physical developments that occur some time at the beginning of puberty, they didn't happen either. Of course, I then asked myself: "Why? How come? What for?" - "Oh, it'll happen. You're just a late bloomer." (Paula, 31 years)

Late developer, we're all late in our family. We all look a bit younger. It'll still happen. (Stephanie, 24 years)

As a central source of stress, all the surveyed women highlighted that they had noticed at an early stage that something was not right in their development but were unable to express this in words, and they were also lacking a suitable point of contact.

I was 21 and then went and got the diagnosis. I asked whether it was necessary that I have periods. Then he (the doctor, addition by interviewer) said: "No, it's just a matter of hormones." Then I pretty much just put up with it for ten years and didn't have any more periods. (Laura, 31 years) 
For three of the Ps, the absence of growth during puberty led to insecurities and teasing. However, once they began hormone therapy, growth continued.

Anosmia was not perceived as a major impairment by the Ps. They do not consider the lack of a sense of smell to be a major deficit. Despite this, the Ps spoke of insecurities in terms of hygiene and fears of not noticing dangers in good time, such as gas leaks or smoke. Nevertheless, this barely represented a constraint on their quality of life.

But having this fact that you can't smell and you also can't change it, you've just got to come to terms with it. (Laura, 31 years)

\section{Interaction between hormone therapy and psyche}

In addition to feelings of shame with regard to her own body and the resulting insecurities when approaching her peers, one $\mathrm{P}$ spoke of severe mood swings and feelings of depression as part of hormone therapy.

I was first given Trisequens. Six months later the effect had subsided. So, none of the positive effects remained, apart from the periods. Then there was Trisequens Forte. This also had a positive effect for six months, at least on the way I felt in general. And then that was it. ... After Trisequens Forte, when they didn't want to give me anything else, after that things pretty much went downhill with my physical health and self-perception, as well as my psyche and everything else. (Paula, 31 years)

During the consultation, I explained to him (the doctor, addition by interviewer) that things weren’t going well for me at all. (Paula, 31 years)

\section{Diagnosis and treatment}

KS was diagnosed among the Ps at 22.8 years on average. For three women, a lack of oestrogen was diagnosed beforehand. For one $\mathrm{P}$, anosmia was diagnosed at the age of 10 . However, no connection with KS was seen at that time. For one participant, KS was diagnosed directly as a result of the diagnosis of KS in her brother. On average, the Ps first attracted attention in connection with KS at 13.4 years. KS was only diagnosed on average 9.4 years later (c.f. $\odot$ Table 1 ).

Of course, we'd known for a long time that I have hormone problems. I was first given substitution when I was 16. We either never told the Gynaecologist that I can't smell because we didn't link the two things at all, or he didn't know. Then, at some point, I went to a Hormone Clinic and just mentioned in passing that I couldn't smell. Then something "clicked" with the member of staff. Since then, I've just assumed that I have Kallmann. (Laura, 31 years)

KS was diagnosed in all the Ps via the lack of a sense of smell and by examining blood test results. When talking about the diagnosis of KS, the Ps describe feelings between shock and fear, but also relief about the clarification and hope for improvement.
"But it's not all that bad. When it's all treated properly, I can still lead a somewhat fulfilled life." That's what he (the doctor, addition by interviewer) said. And I was so shocked back then because, apart from this feeling of "something isn't right about me, something is strange and different", otherwise I didn't know anything at all, and then bam! that gets thrown at you. (Jeannette, 24 years)

When you finally know what it is, you might finally be able to do something about it. Now that you know what it is, you can tackle it. The diagnosis itself actually brought out the sun. (Paula, 31 years)

The examinations as part of treatment were described as stressful by all of the Ps. The lack of support from doctors was addressed by four of the five Ps, as these did not pay enough attention to their mental stress during hormone treatment.

Medical treatment began with the diagnosis. It was approximately the same for all the women. It took place by administering sex hormones. Four Ps tolerated this treatment well; one P, however, had great difficulties with this treatment, which expressed themselves in depressive moods and physical symptoms. For one $P$ initially diagnosed with oestrogen deficiency, medicinal treatment was nevertheless altered due to depressive moods after KS was diagnosed. KS was diagnosed in this patient shortly before the interview, and she hoped that the diagnosis would bring with it optimised medication along with an improvement in her mental condition.

\section{Physical development following hormone treatment} The Ps perceived the physical development stimulated by medication as a great relief.

I was so delighted, I was so proud! Oh, my! That first blood-stained sanitary towel that I had there. I really wanted to stick it into a diary or wave it in the air! (Jeannette, 24 years)

The following physical developments associated with the hormone treatment were described: breast growth, growth of the mammary glands, growth of pubic hair, start of periods, widening of the hips. One P found that the physical development triggered by medication was not sufficient for her and her body did not become feminine enough. She subsequently decided to have breast enlargement surgery.

\section{Sexuality}

Four Ps described their sex lives as very problematic and stressful. They experienced sexual disinterest prior to hormone therapy. Two of them suffered from low or non-existent libido, even with continued treatment. Two women said that no libido developed despite the hormone therapy, which led to problems in their relationships and put the Ps under severe pressure.

At the most, it only played a role in this sense if it's linked to Kallmann, which I'm assuming here, that my sexual activity just isn't particularly high. (Laura, 31 years)

In addition to this, both these women and two other women were severely inhibited as soon as it came to sexual contact. This led to insecurities and avoidance of contact with the opposite sex. 
Table 2 Age at first sexual intercourse and first sexual experience without SI.

\begin{tabular}{|c|c|c|c|}
\hline Participant No. & $\begin{array}{l}\text { Name/ } \\
\text { synonym }\end{array}$ & Age 1st SI & $\begin{array}{l}\text { Age } 1 \text { st sexual } \\
\text { experience } \\
\text { without SI }\end{array}$ \\
\hline 1 & Jeannette & 19 & 19 \\
\hline 2 & Laura & 21 & 19 \\
\hline 3 & Marie & 21 & 16 \\
\hline 4 & Paula & 17 & 14 \\
\hline 5 & Stephanie & 19 & 18 \\
\hline Mean value & & 19.4 & 17.2 \\
\hline Standard deviation & & 1.50 & 1.93 \\
\hline Median & & 19 & 18 \\
\hline Range & & 4 & 5 \\
\hline
\end{tabular}

The average age of the Ps at first sexual intercourse was 19.4 years (range 3 years, median 19 years). The Ps' first sexual contact without sexual intercourse (SI) was at 17.2 years (range 5 years, median 18 years). A detailed breakdown is given in $\mathbf{O}$ Table 2.

As I had a really horrible body image, there was naturally no lust felt at all. Because this embarrassment was in the foreground. (Marie, 44 years)

Yes, the first step, before I got together with the guy, was that I tried to satisfy myself, which didn't really work either. That was the first step and the first interest in that. Then just a bit of petting with him. But it wasn't much more than that. With my present husband, it took around two years before we were able to sleep with each other for the first time. (Laura, 31 years)

First of all, you had to find a guy who didn't think you were a child. Then you had to like him. But whenever it got to the point where he put his hand under your blouse or even above it, hey! Back off! Back off! So, it wasn't easy. Then it was more about how to endure it, how to bring yourself to do it and not show the other person that you're not like other people. (Paula, 31 years)

\section{Fertility}

Introducing ovulation in women with $\mathrm{KS}$ requires treatment with HCG, hMG or GnRH $[9,10]$. The chances of conception are $30 \%$ per ovulation [9]. Treatment with $\mathrm{LH}$ and FSH increases the chances to $70 \%$ [9].

The diagnosis of KS triggered depression and fear in all the women with regard to pregnancy, as well as uncertainties relating to medical treatment.

What was really bad for me was that when he (the doctor, addition by interviewer) told me what was wrong with me, he then told me, "it's possible that you won't be able to have children". I've got to say that was such a slap in the face. My dream is to have children! (Stephanie, 24 years)

Well, in this respect, I'm more worried about the issue of what my child will inherit or what it'll be like for him. (Laura, 31 years)
One P resigned herself to not having children. One P, who was already pregnant, described the corresponding medical treatment as good. Three additional Ps with a desire to have children said they would rely on appropriate medical support when the subject of children became relevant for them later on.

Yes, having the certainty or knowing what will happen to my children, if I should ever have children, so whether they could have this as well and what this chance is, et cetera. Simply getting more information when the time comes. (Stephanie, 24 years)

\section{Coping strategies, resources and assistance} in handling $\mathrm{KS}$

The Ps found it helpful to have conversations about KS within their family, with friends, and later with their partners, who handled the subject of KS in an understanding way. For one patient, the emphasis on normal development by her parents was particularly valuable. Talking to other sufferers and the dissemination of information via the Internet also helped to provide relief. It was important to the Ps that they were well-informed about KS. If treatment reduced the limitations caused by KS, the Ps perceived this normalisation of their life situation as especially positive.

In order to reduce fear and uncertainties, three Ps underwent psychotherapy, during which they achieved good results. Besides psychotherapy, one of these Ps also made use of additional therapeutic services in the psychosomatic field, to which she attributed the development of improved body perception and a healthy self-image.

I would always swear that it has nothing to do with hormones, but it's simply my psychotherapy. (Marie, 44 years)

Discussing her own body perception also helped her to develop a better feeling about her sexuality.

I kept noticing how this shame side of me became smaller and the lust side bigger, that suddenly a great deal was going well. (Marie, 44 years)

One $P$ received particularly intensive assistance from her parents before and after diagnosis, who placed great importance on normalising her development, so that, consequently and thanks to an early diagnosis, she developed hardly any insecurities with regard to her body. She also found discussions with her brother, who is also affected by KS, to be positive.

As I said, from my brother, who's also affected, that's always helped me to cope with it, how he's reacted in the situation. (Stephanie, 24 years)

At the time I was always told: you're developing in a really normal way. So, it was always emphasised that you're completely normal. They're just sort of being replaced, your hormones. Physical development happens just the same way as for everyone else. That's why I thought, it'll just happen, maybe a bit later than for others, but it'll just happen. That's why it was completely normal for me, just like every other teenager, too. (Stephanie, 24 years) 
The Ps said the following were particularly desirable when handling KS:

- A comprehensive view of KS including its psychosocial effects

- Psychotherapeutic support

- A better and more sensitive explanation of KS as well as more interest among doctors in an individual's problems regarding physical development

It's not a problem, this whole hormone part of it, you can regulate and adjust all that. But what it means for a girl to be right in the middle of it, nobody understood that and no one ever spoke to me about it. At least, that someone could have drawn my attention to the fact that it also has social implications and mental ones and also someone could at least have shown me that I could also get psychological help. I mean, as a child, I'm not going to think of that by myself." (Jeannette, 24 years)

No one understood that my problem is absolutely not some hormones, but instead how to get by in my social environment! (Jeannette, 24 years)

\section{Discussion}

The interview material made it possible to obtain a differentiated and broad range of data concerning the experience of KS among women. The study results support the statements by Tsimaris et al. [13] on stresses caused by diagnosis and on later mental pressures $[13,14]$. The Ps reported on inhibitions when coming into contact with the opposite sex and on difficulties in allowing physical proximity and intimacy, caused by the shame they felt about their own bodies. Two of the five Ps felt that their quality of life was restricted by their low libido [13] and due to the asso-
Table 3 Categories of qualitative assessment.

\begin{tabular}{|l|l|}
$\begin{array}{l}\text { 1. The path to diagnosis and the } \\
\text { diagnosis of Kallmann Syndrome }\end{array}$ & Assumptions beforehand \\
& Pubescent physical development \\
& Diagnosis \\
& Stress before and during the \\
2. Medical treatment following & Medication \\
diagnosis & Treatment effect \\
\hline $\begin{array}{l}\text { 3. Individual somatic symptoms } \\
\text { of KS }\end{array}$ & Height \\
& Sense of smell \\
\hline $\begin{array}{l}\text { 4. Mental and psychosocial effects } \\
\text { of KS }\end{array}$ & - Sertility \\
\hline 5. Coping strategies & Self-worth \\
& Social relationships \\
\hline
\end{tabular}

ciated impacts on their relationships. An adjustment to medication only provided relief to a limited extent [15], including with regard to depressive moods before and after hormone therapy. The significance of the results on the influence of medication on the libido and mood is limited because of the small sample sizes, as shown in the methodology section, and also the qualitative, explorative research design. As a result, no further statements about the effects of hormone therapy on mood, drive and libido can be made as part of this study. The medical literature on the influence testosterone has on the mood of men affected by KS $[15,17,29,30]$ and the research findings of the study by Hofmann et al. [1] on men affected by KS who experience mood swings much more frequently allow us to assume - even with regard to the small female patient sample - that even more women with KS could be affected by depressive moods. Further research into

Table 4 Study results at a glance.

\begin{tabular}{|c|c|}
\hline Body perception and shame & $\begin{array}{l}\text { - Confusion and insecurities regarding the absence of expected pubescent development } \\
\text { - First inklings and fears about delayed development, which are difficult for the Ps to address } \\
\text { - Delaying of a medical clarification; hope of being a "late bloomer" } \\
\text { - Shame regarding lack of physical development (particularly menstruation) } \\
\text { - In some cases, problems with growth } \\
\text { - Anosmia of little concern }\end{array}$ \\
\hline Effects of hormone therapy on the psyche & - Mood swings and depressive feelings as part of hormone therapy \\
\hline Diagnosis and treatment & $\begin{array}{l}\text { - In some cases, initial diagnosis of oestrogen deficiency } \\
\text { - Fear, shock, but also relief and hope for a cure due to medical diagnosis } \\
\text { - Examinations are perceived as stressful, as too little attention is paid to the mental aspects, in particular } \\
\text { - Treatment of KS with hormone therapy (no difference to treatment for oestrogen deficiency); } \\
\text { change to hormone therapy following KS diagnosis for only one P }\end{array}$ \\
\hline Physical development following hormone treatment & - In some cases, physical development was perceived as insufficient \\
\hline Sexuality & $\begin{array}{l}\text { - Sexual disinterest prior to hormone therapy } \\
\text { - In some cases, very low sexual interest, even during hormone treatment } \\
\text { - Feelings of shame and inhibitions in allowing intimacy }\end{array}$ \\
\hline Fertility & $\begin{array}{l}\text { - Uncertainties regarding pregnancy } \\
\text { - Reliance on good medical treatment }\end{array}$ \\
\hline $\begin{array}{l}\text { Coping strategies, resources and assistance } \\
\text { in handling KS }\end{array}$ & $\begin{array}{l}\text { - Conversations } \\
\text { - Emphasis on normal physical development } \\
\text { - Good dissemination of information } \\
\text { - Physical development through hormone therapy } \\
\text { - Where required, offers of psychotherapy or sex therapy }\end{array}$ \\
\hline Desire for better handling of KS & $\begin{array}{l}\text { - Comprehensive view of KS, including its mental and psychosocial impacts } \\
\text { - More sensitive explanation by doctors } \\
\text { - Where required, assistance through psychotherapy or sex therapy }\end{array}$ \\
\hline
\end{tabular}


the effect of various medications, the different dosages and the effect on the libido and mood are required as part of a larger study.

None of the physical malformations, such as renal agenesis, bimanual synkinesis, cleft palate, and tooth anomalies, that can occur in KS with a prevalence of $5-10 \%[3,6,8]$, were present in the investigated sample. Stress due to osteoporosis was not addressed [8].

As part of the study, it became clear that there was a misdiagnosis or initial diagnosis of oestrogen deficiency in some cases. In the sample, it took an average of 9.4 years from the initial diagnosis until the diagnosis of KS. The problem of misdiagnosis or initial diagnosis of oestrogen deficiency has scarcely been investigated in the corresponding medical literature $[9,13]$. Further studies in this regard are advisable in order to verify how often such misdiagnoses occur in KS in women (which could also be a reason for the differences in prevalence among the gender groups) and whether medical treatment could be further optimised through a correct diagnosis. It can, however, be assumed that most women largely felt they were receiving adequate medical care with the diagnosis of oestrogen deficiency and thus did not make any further efforts to obtain a medical diagnosis.

Besides the appropriate coordination of medical treatment, psychotherapeutic support and, particularly where necessary, support relating to sex therapy and sex education are to be advised as a matter of urgency $[13,17]$. While Han and Bouloux [17] express this recommendation for men, the present research findings suggest that support within sex therapy is particularly relevant for women due to the low libido and dry vagina [13]. Furthermore, the Ps found it stressful that their bodies did not develop appropriately during puberty, which led to major insecurities with regard to contact with girls of the same age and, above all, with boys.

The account of one P can serve as an example of good, successful support for those affected. During puberty, this P experienced hardly any stress and impacts caused by KS and did not feel restricted by KS, even in later life. She stressed that the people around her always emphasised the normalisation of her development. She also had the opportunity to exchange experiences with another sufferer, her brother. Her early diagnosis was followed by appropriate treatment.

This explorative study raises further in-depth research questions that could contribute to more differentiated findings and better, more appropriate treatment for those affected:

- How do the various medications influence the mood and libido of the affected women?

- What effects does early appropriate medication have on physical development and self-perception?

- Does an early diagnosis help to reduce the mental impacts caused by the lack of physical development?

- How relevant, with regard to the applied hormone therapy and mental impacts, is the difference between the initial diagnosis of oestrogen deficiency and the final diagnosis of KS?

- What kinds of psychotherapeutic services are particularly helpful for those affected and what form does appropriate therapeutic support take?

- How can support within sex therapy and sex education be shaped?

Further research into the mental impact of KS on women is advised as there are very few systematic studies in this research field, even fewer than on the mental impacts of KS among men.

\section{Conclusions}

$\nabla$

It became clear through the study that there are not only direct mental impacts and stresses due to the hormone deficiency, but also indirect mental impacts and stresses due to the lack of physical development, such as low libido or the development of feelings of shame about one's own body, and as a result of social difficulties in how to make contact with men. KS should therefore not be viewed as a purely somato-medical problem, but instead the psychosocial aspects of KS should also be perceived and noted as a limitation on quality of life. For women who react sensitively to hormone treatment with mood swings, provisions should be made to offer relief in this respect.

Psychological advice or a psychotherapist is to be recommended during the diagnosis of KS as well as, where required, assistance in the form of sex education or sex therapy.

\section{Conflict of Interest}

$\nabla$

None.

\section{References}

1 Hofmann J, Watzlawik M, Richter-Appelt H. Leben mit dem KallmannSydrom - narrative Erfahrungsberichte von Männern. Z Sexualforsch 2013; 26: 99-121

2 Mayring P. Qualitative Inhaltsanalyse. Grundlagen und Techniken. Weinheim: Beltz Verlag; 2007

3 Dodé C, Hardelin J-P. Kallmann syndrome. Eur J Hum Genet 2009; 17: 139-146

4 Mitchell AL, Dwyer A, Pitteloud N et al. Genetic basis and variable phenotypic expression of Kallmann Syndrome: towards a unifying theory. Trends Endocrinol Metab 2011; 22: 249-258

5 Behre HM, Tüttelmann F, Ledig S et al. Hypogonadotroper Hypogonadismus aufgrund eines IHH oder KS beim Mann. medizinische genetik 2011; 23: 254-258

6 Kaplan JD, Bernstein JA, Kwan A et al. Clues to an early diagnosis of Kallmann syndrome. Am J Med Genet Part A 2010; 152 A: 2796-2801

7 MacColl G, Quinton R. Kallmann's syndrome: bridging the gaps. J Pediatr Endocrinol Metab 2005; 18: 541-543

8 Pallais JC, Au M, Pitteloud N et al. Kallmann syndrome. GeneReviews [Internet]. 2011. Online: http://www.ncbi.nlm.nih.gov/books/ NBK1334/; last access: 15.01.2013

9 Skalba P, Guz M. Hypogonadotropic hypogonadism in women. Endokrynol Pol 2011; 62: 560-567

10 Battaglia C, Salvatori M, Regnani G et al. Successful induction of ovulation using highly purified follicle-stimulating hormone in a woman with Kallmann's syndrome. Fertil Steril 2000; 73: 284-286

11 Balasch J, Fábregues F, Carmona $F$ et al. Ovarian luteinizing hormone priming preceding follicle-stimulating hormone stimulation: clinical and endocrine effects in women with long-term hypogonadotropic hypogonadism. J Clin Endocr Metab 2009; 94: 2367-2373

12 Brämswig J, Dübbers A. Disorders of pubertal development. Dtsch Ärztebl Int 2009; 106: 295-304

13 Tsimaris T, Vrachnis N, Iliodromiti $Z$ et al. Long-term follow-up of adolescent and young adult females with hypergonadotropic hypogonadism. Int J Endocrinol 2012; 2012: 862892

14 Land C. Vorzeitiger, verspäteter und ausbleibender Pubertätsbeginn. Monatsschr Kinderheilkd 2012; 160: 626-637

15 Deutsche Gesellschaft für Kinderheilkunde und Jugendmedizin (DGKJ); Deutsche Gesellschaft für Endokrinologie (DGE); Arbeitsgemeinschaft der Wissenschaftlichen Medizinischen Fachgesellschaften (AWMF), Hrsg. Pubertas tarda und Hypogonadismus: Leitlinie der DGKJ, erarbeitet von der Arbeitsgemeinschaft Pädiatrische Endokrinologie (APE) sowie der DGE, Sektion Pädiatrische Endokrinologie und Diabetologie. Düsseldorf: AWMF; 2011

16 Denschlag D, Keck C. Das Kallmannn-Syndrom. Reproduktionsmedizin 2003; 19: 76-80 
17 Han TS, Bouloux PMG. What is the optimal therapy for young males with hypogonadotropic hypogonadism? Clin Endocrinol (Oxf) 2010; 72: 731-737

18 Hefner J, Csef H, Seufert J. Kallmann-Syndrom. Pathophysiologische Grundlagen und Darstellung zweier Patientengeschichten. Nervenarzt 2009; 80: 1169-1175

19 Bobrow NA, Money J, Lewis VG. Delayed puberty, eroticism, and sense of smell: a psychological study of hypogonadotropinism, osmatic and anosmatic (Kallmann's syndrome). Arch Sex Behav 1971; 4: 329-344

20 Neemuchwala $P$. On coming to terms with losing something we never had - a psychotherapist's perspective. 1999. Online: http://www. hypohh.net/pdffiles/info3pro.pdf; last access: 08.12.2012

21 Neemuchwala P. Psychological aspects of pubertal delay - a psychotherapist's perspective. 1998. Online: http://www.hypohh.net/ pdffiles/info2pro.pdf; last access: 08.12 .2012

22 Neemuchwala P. Towards a theory of self-esteem - a psychotherapist's perspective. 1998. Online: http://www.hypohh.net/pdffiles/info1pro. pdf; last access: 08.12.2012
23 Hofmann J, Anonyma, Richter-Appelt H. Das Kallmann-Syndrom. Medizinische Hintergründe und psychische Folgen anhand eines Erfahrungsberichts. Z Sexualforsch 2009; 23: 1-15

24 Meyenburg B, Sigusch V. Kallmann's syndrome and transsexualism. Arch Sex Behav 2001; 30: 75-81

25 Lamnek S. Qualitative Sozialforschung. Weinheim: Beltz Verlag; 2010

26 Schulz J, Kurz S, Zelger J. Die GABEK-Methode als Ansatz zur Organisationsentwicklung. IT + B-Forschungsberichte Nr. 32. Bremen: Institut Technik \& Bildung - Bibliothek; 2008

27 Kurz S, Zelger J, Schulz J. GABEK als Methode zur kollegialen Organisationsentwicklung. 2007. Online: www.rebiz-bremen.de/sixcms/detail. php?gsid=bremen59.c.1466.de; last access: 15.01.2013

28 Lucius-Hoene G, Deppermann A. Rekonstruktion narrativer Identität. Ein Arbeitsbuch zur Analyse narrativer Interviews. Opladen: Leske \& Budrich; 2004

29 Leiber C, Wetterauer $U$, Berner M. Testosteron und Psyche. Urologe 2010; 49: 43-46

30 Dandona P, Rosenberg MT. A practical guide to male hypogonadism in the primary care setting. Int J Clin Pract 2010; 64: 682-696 